\title{
CAN YOU SEE HOW IT SMELLS? WHAT EYE TRACKING CAN TELL US ABOUT THE SHELF MANAGEMENT OF LUXURY PERFUMES
}

Anida Krajina, Melika Husić-Mehmedović, Kemal Koštrebić

\section{Abstract}

The purpose of this paper is to advance the theory and contribute to the practice of luxury perfumes' shelf management by decoding the relationship between attention on the shelf, purchase decision-making, and brand recall. It employs an eye-tracking experiment to analyze attention spans and fixations, which is combined with a questionnaire to uncover recall and purchase intent. The research identifies attention patterns and the influence of attention on recall and purchase intention. It further reveals the main factors that influence attention on the shelf in the luxury perfume industry. This is a milestone for further elaboration on the benefits of the fashion mainstream for luxury perfumes and the debate regarding whether luxury perfumes should be treated similar to mainstream fashion or similar to any other product in basic shelf management rules. This study enables shelf managers and marketers to place the perfumes both on the shelf and in consumer minds to maintain a top-of-the-mind brand position. Managerial implications are significant and address perfume industry packaging as well as shelf positioning.

Keywords: eye tracking, visual attention, shelf management, luxury products, purchase intent

JEL Classification: $M 30$

\section{INTRODUCTION}

Despite the vast amount of research generated within the field of consumer visual attention in stores, there is a lack of studies focusing on the luxury, fashion, and perfume category, and this category is somewhat specific. Fragrance consumption is in a product category of its own, as it is often a symbolic product that demands a high level of involvement from the consumer, although it may not be priced like other high-involvement products. Consumers purchase this product based on associative links and self-image or through emotional connections, whether for themselves or by association.
Anida Krajina, $\mathrm{PhD}$ (corresponding author) Digital Marketing Specialist and Marketing Researcher Optiweb, Škofja Loka E-mail: anida.krajina@gmail.com Address: Polanškova ulica 16, 1231 Ljubljana, Slovenia ORCID: 0000-0001-8932-3428

Melika Husić-Mehmedović, PhD Professor School of Economics and Business, University of Sarajevo

E-mail: melika.husic@efsa.unsa.ba ORCID: 0000-0002-0802-2752

\section{Kemal Koštrebić}

Research Manager GapFish GmbH in Berlin, Germany E-mail:kemal.kostrebic@gmail.com 
Recognition, recall, and purchase decision in this category are highly influenced by the brand itself and specific design. According to findings from previous studies, brands that are positioned near the center of the shelf (and thus in the middle of the visual span) receive the majority of the attention (Chandon et al. 2009). However, the same study demonstrates that improved attention through in-store marketing activity strongly influences consumer behavior at the point of purchase but only to a certain extent. Shelf management war may be useless on a larger scale and especially so in the luxury category or the product-specific fashion mainstream, which includes perfumes. Therefore, the authors aim to broaden the knowledge and research on overall shelf management in the perfume category, especially with more focus on visual attention. Hence, the specifics of packaging in the luxury perfumes industry and its influence on shelf management and visual attention is discussed. This study is a milestone for further elaboration on the benefits of the fashion mainstream for luxury perfumes and the debate regarding whether luxury perfumes should be treated similar to mainstream fashion or similar to any other product in basic shelf management rules.

The goal of this study is to propose ways to improve shelf management in the luxury perfumes category, including recognizing in which areas of the shelf products must be placed so they receive attention and can be recalled by consumers. The importance of the focus area as well as peripheral areas for product recognition and purchase intention are examined. The research achieves its objectives by addressing the following research questions:

RQ1. How does brand familiarity influence visual attention?

RQ2. How do package features change common knowledge on shelf management?

RQ3. Is the effect of attentional spotlight only subliminal, or does it transfer to consciousness and evoke purchase intention?

$\mathrm{RQ} 4$. Is the category captain the true captain of the shelf?

RQ5. Is shelf management irrelevant in the luxury perfume category?

RQ6. To what extent do luxury perfumes benefit from the fashion mainstream?

For this purpose, we conducted a two-phased study with an experiment utilizing eye-tracking analysis and traditional questionnaire-based research preand post experiment. The experiment was controlled in laboratory conditions utilizing custom-made, randomized stimuli for each respondent. The questionnaire allowed us to address brand recognition, brand recall, and purchase intention of the observed products in the eye-tracking study. As this is exploratory research, the research questions are proposed, thus enabling further research ideas. Eye tracking is rarely utilized in luxury or fashion research, and readers may benefit from these novel findings in the fashion industry, while the significant managerial implications confront shelf management, packaging in the perfume industry, and shelf positioning.

\section{THEORETICAL BACKGROUND}

Luxury goods are those for which the mere usage or display of a particular branded product brings prestige to the owner apart from any functional utility (Husić and Čičić 2009), which provides the product with high brand awareness and a global reputation (Kim et al. 2019). Rambourg (2014), in his market research on luxury products, places perfume at the base of the pyramid of affordable luxury. This suggests that the positive values conveyed by luxury tend to be transferred to perfume's pleasantness (Baer et al. 2018). Glamorous and stylish, perfume is an evocative product that stimulates the senses. Baer and colleagues (2018) suggested that the basis for consumer choice for this product should be based on olfactory preference; however, the process-related decisionmaking is more complex. The mature consumer's purchase decision-making in this product category is often associated with long-standing, established, luxury fragrance brands (Drylie-Carey and Stewart 2018).

Olfaction, through the ages (Le Guérer 2002), has been distinguished in the sensory landscape for its particular and close relationship with the world of emotions. Odors affect behavior (Bensafi et al. 2002a, 2002b), mood, and well-being (Alaoui-Ismaïli et al. 1997; Rétiveau and Milliken 2004; Warrenburg 2005) as well as cognitive processes, such as memory and preference acquisition (Leppänen and Hietanen 2003). Preference for a specific perfume relies on affective processes, such as attachment and the nostalgia related to it (Lambert-Pandraud and Laurent 2010) or a striving for an ideal self (Belk 1988). Moreover, the sense of smell is intricately connected to memories, and smell may evoke memories and feelings (Aydinoğlu and Sayin 2016). These characteristics make fragrance a personal product.

Attention is important in defining and interpreting the decision-making process. According to Orquin and Loose (2013), more accurate assumptions about decision-making could be made based on prior attention and eye-movement research. Some research has 
explored the relationship between visual attention and choice, demonstrating a positive effect of visual attention measures on brand choice (Pieters and Warlop 1999). Attention further leads to recall and recognition (Krajina 2019). Moore and colleagues (2013) suggest that when a stimulus (ads, packaging, image, or color) generates sufficient attention to gain recall or recognition, moderate congruity offers the most favorable attitudes toward the stimulus. Altogether, much can be learned from how consumers scan their environment for relevant information to make the choices that interest marketers.

\subsection{Visual Attention in the Spotlight}

Key questions in attention research include how attention is attracted and how some objects pass the consciousness threshold while others do not (due to the selectivity of the brain and the reduction of cognitive overload). From the consumer behavior perspective, consumer attention represents the degree to which consumers focus on specific stimuli that are exposed. The reasons behind dedicating attention to objects in the visual span are deeply rooted in consumer values (Krajina 2019). Bialkova and van Trijp (2010) explain that a consumer's attention may be directed toward a stimulus because it is meaningful to the consumer's goals (goal-directed attention) or because the stimulus is highlighted as particularly salient within the visual field (stimulus-driven attention). Eye-tracking movement measures were built on theories of consumer attention and choice and therefore are often utilized in examining visual attention (Pieters and Warlop 1999).

Visual attention appears to be crucial in acquiring information about brands in consumer choice contexts (Pieters and Warlop 1999). Underwood and colleagues (2011) explain that package pictures increase shoppers' attention to a brand. Moreover, Bialkova and colleagues (2013) posit that the information density (when information cues a visual scene) represents the key factor for consumer attention to information. Standard visual attention research argues that salient objects fall into the visual span (and thus the consumer's focus) more easily than nonsalient objects (Goldberg and Kotval 1999; Bucher and Schumacher 2006). Merchandise displays are of the utmost importance in retail settings. A somewhat general assumption is that greater details related to a given object (e.g., brand name) require a consumer's fixation to be centered on that object to recognize the detail. When examining shelf management, brands positioned near the center of the shelf (and thus in the middle of the visual span) receive the majority of the attention (Chandon et al. 2009). Retailers rely on displays to be silent salespeople, to draw consumers into the store, and to motivate them to touch, evaluate, and purchase products (Huddleston et al. 2015). This paper addresses consumers' familiarity with the brand compared to other factors, such as shelf positioning and attention, and how this phenomenon can be applied to luxury perfume shelves. Therefore, the first research question is proposed:

\section{RQ1: How does brand familiarity influence visual attention?}

Clement and colleagues (2013) examined the relationship between abundant in-store stimuli and limited human perceptual capacity by investigating the influence of package design features on visual attention. This group of authors conducted both the instore and laboratory data collection and demonstrate that consumers have fragmented visual attention during grocery shopping; furthermore, their visual attention is simultaneously influenced and disrupted by the shelf display (Clement et al. 2013; Tonkin, Ouzts, and Duchowski 2011). The aforementioned research initiatives mainly examined the focus area and attentional spotlight, which assumes that visual attention is allocated to a certain location in the visual field and that items at that location are processed more intensively than items at other locations (Hubner, Steinhauser, and Lehle 2010).

Authors additionally suggest that package silhouette and shape attract visual attention, while package text elements have a negative influence on visual attention (Clement et al. 2013). The design of perfume packaging is mainly concerned with the former process to seduce consumers by subconsciously manipulating moods and thereby convincing them to buy (Petersson McIntyre 2013). Some salient features can steal the attentional spotlight regardless of their position on the shelf, and considering the specifics of perfume packaging, the second research question is presented:

\section{RQ2: How do package features change common knowledge on shelf management?}

Being in the attentional spotlight is important, but it is not the only factor by which consumers make their purchase. In addition to noting the object in the visual span, the aspect of reexamination needs to be included. Reexamination occurs before the evaluation (which includes consideration, choice, and recall). The main critique raised by Chandon and others (2009) is 
that if consumers can recall the brands that are not positioned centrally, then the fixation does not have to be centered, as traditionally assumed. Previous eye-tracking studies have illustrated that eye fixations, rather than peripheral vision, increase memory of the objects of fixation (Pieters, Warlop, and Wedel 2002). Contrary to these assumptions, Chandon and others (2009) posit that some shoppers recalled more brand names but noted fewer brands on the shelves. Bigne and colleagues (2016) have found that slow eye movements between brands led to additional brand purchases within a category, highlighting that the time buyers spend on the first choice is a key driver for additional purchases.

The next research question assesses the connection of attentional spotlight with the final decision:

RQ3: Is the effect of attentional spotlight only subliminal, or does it transfer to consciousness and evoke purchase intention?

\subsection{Perfume Category Shelf Management}

A review of the perfume industry has found that the market has reached a level of saturation, with approximately 300 new fragrances being launched yearly (Richmond 2012). This creates a countless number of stimuli initiated by brands to attract attention and induce purchase. Brand familiarity is an essential source of information about a brand, which is enhanced by accumulated experiences with a brand or frequent exposure to it (Alba and Hutchinson, 1987). Brand familiarity examines a consumer's brand knowledge structure and leads to processing behavior, meaning that brand familiarity positively influences the involvement with the brand (McClure and Seock 2020).

The combinations of various perceptional elements of brand equity have strong impacts on brand purchasing intention (Foroudi et al. 2018). The results from Foroudi and colleagues (2018) support the importance of brand perception for the fashion industry in particular, which needs to be more interactive to increase brand purchasing intention and brand loyalty. Therefore, it is logical to question the connection between brand popularity and visual attention: do category leaders attract attention on the shelf due to their brand awareness, or do they compete for visual attention like any other brand on the shelf? Therefore, the next research question states the following:

RQ4: Is the category captain the true captain of the shelf?
Industry sources report that perfume is often sold based on its popularity, endorsement (usually linked to a celebrity), and overall packaging. Mature consumers' purchasing decision-making is often linked to older or long-standing luxury brands, especially in the fragrance market (Drylie-Carey and Stewart 2018). Due to gender associations with femininity and seduction (Petersson McIntyre 2013), the perfume industry has struggled to ascertain ways to market fragrance to men. When a woman buys perfume, she buys much more than simply fragrant fluids. The perfume image, its promises, its scent, its name and package, the company that makes it, the stores that sell it - all become a part of the total perfume product. Perfume is a strong symbolic product (Aaker 1997) that has been demonstrated to enhance self-esteem and lift moods (Edwards 2015). Based on eye-tracking research by Cuesta and colleagues (2020), in perfume advertising, women tend to be more observant and emotional, paying more attention to flowers, colors, and the design of the container. However, men pay more attention to the perfume cap shape and the brand logo (Cuesta, Paida, and Buele 2020). This proves the necessity of well-planned targeting of the market and thus the creation of overall marketing for the selected target; the marketing includes bottle shape, color, and package design to attract attention and enhance purchase by the selected target.

Luxury brands share a similar concept with perfume: buying luxury goods is synonymous with buying status. Therefore, social groups buy luxury brands to achieve a common goal - to demonstrate their prestigious status (Rashid and Chattaraman 2019). Luxury stands for quality and rarity and holds strong hedonic meanings (Berthon et al. 2009). Beyond the functional benefits, luxury consumption relies on emotional and sociopsychological benefits (Vigneron and Johnson 1999, 2004) delivered through the symbolism of an expensive yet thriving experience of unicity and aesthetics (Belk 1988; Megehee and Spake 2012). The luxury fashion brands should develop communication strategies based target consumers' head and heart to create brand-loyalty and form a lifelong love or attachment to the brand. Consumers purchase this product based on associative links and self-image or through emotional connections, whether for themselves or by association. There are high levels of loyalty, nostalgia, and attachment surrounding this product sector, while contrasting perceptions are pointed out by Carey and colleagues (2016) and are emanating from the industry and consumer views.

Consequently, it is logical to wonder whether and to what extent shelf management in the luxury 
perfume category influences purchase or whether the decision is made before consumers enter the store. Moreover, how does this fashion mainstream or current popularity of a brand influence visual attention, shelf management, and purchase decisions? Hence, the following research questions are proposed.

RQ5: Is shelf management irrelevant in the luxury perfume category?

RQ6: To what extent do luxury perfumes benefit from the fashion mainstream?

\section{METHODOLOGY}

This exploratory research was conducted in two stages: (a) a biometrical experiment with an eye tracker and (b) a quantitative survey both pre- and postexperiment. There are various benefits of utilizing the eye-tracking method in analyzing shelf management and packaging benefits of the product, but the ideal outcome occurs when these techniques are combined with an additional survey-based method (Leckner 2012). Recent studies have concluded that important insights can be gleaned by combining eye movements and a form of retrospective verbal reports (Helle 2017; Krajina 2019). Thus, the eye movements create an assumption about attention and preference (Karmarkar and Plassmann 2019; Krajina 2019), but it appears beneficial to combine eye tracking with other methods for deeper understanding (Krajina 2019).

Both stages of the study were conducted with a sample of 50 adult female respondents in total. The female sample who participated in this research was collected at the university by targeting female students in master studies and the final year of bachelor studies as well as their contacts (implementing the hybrid snowball approach). In addition to gender, the condition to participate in the study was that they had purchased female luxury perfume in the past 2 years, either for themselves or as a gift. The participants of this convenience sample had normal, or correctedto-normal, and full-color vision. Before and after the collection of eye-tracking data, participants were provided with the questionnaire to complete. By coding the respondents' answers, anonymity was guaranteed.

\subsection{Biometrics}

In the biometrical part of the study, the eye tracker, under controlled laboratory conditions, was utilized. The usage of psychophysiological techniques is not new in consumer research; however, brands, retailers, and market researchers tend to assert that the newest behavioral tracking and biometrical tools are designed to allow them to learn what consumers want and need.

The eye tracker measured total fixation time (TFT), fixation number (FN), average fixation duration (AFD), and saliency. For visualization, heat maps were utilized. What appears as smooth and conscious eye movements, in reality, consist of eye fixations (during which the eye remains relatively still for approximately $200-500 \mathrm{~ms}$ ) separated by rapid jumps, called saccades, which average $3^{\circ}-5^{\circ}$ in distance (measured in degrees of visual angle), last $20-40 \mathrm{~ms}$, and allow no information useful for scene perception to be acquired.

The experiment included an in-depth real-user evaluation with an eye tracker on a selection of luxury perfumes. The lists of the global market leaders and 20 top sellers in 2019 (as rated in an interview with a category expert) were obtained. Furthermore, the stimuli - photos of perfumes on shelves - were designed in photo editing software with white backgrounds to avoid distractions. The device utilized for eye tracking was developed by the Eye Tribe (http:// theeyetribe.com/), model ET1000, which captures eye gazes at $30 \mathrm{~Hz}$. The device features a video camera panel mounted above the computer display. The remote system means that eye movements were filmed from a distance and did not require physical contact with a person. This improved the ecological validity of the study (Gidlöf et al. 2012). Before measurement, the eye tracker was individually calibrated for each respondent, and except for a short calibration phase, the setup allowed users to view the screen naturally without the need for a head mount. In the analysis, OGAMA software was utilized for raw data output, while SPSS was utilized to clean the data and compile descriptive statistics.

During the experiment, subjects were comfortably seated at the desk at a distance of approximately 60 $\mathrm{cm}$ from a computer display. The laboratory setting affects ecological validity (Clement 2013; Tonkin et al. 2011), but it allows control over factors such as shelf position, which influences the consumers' attention (e.g., Chandon et al. 2007; Husić-Mehmedović et al. 2017). Attention studies are often performed within controlled laboratory conditions so that consumers' visual attention is influenced solely by the packaging features and design (Clement, Kristenen, and Grønhaug 2013). Subjects were instructed as to the specific experiment tasks and procedures. Eye tracker was calibrated to each, utilizing the randomized 
cursor on the screen, and software noted the coordinates of the sight focus in two sessions of 4 points; the calibration was accepted if there was less than $1^{\circ}$ of visual angle error (on both the $y$ - and $x$-axes). The individual calibration for each participant in an eye-tracking study is important for different reasons. The eyeball radius varies by up to $10 \%$ between adults, and it may have a different shape, which influences the geometrical values underpinning the calculation of gaze direction (Holmqvist et al. 2011). The eye tracker utilizes a high-speed camera, which records the angle of light that is reflected from the eye and identifies the location on the screen where the person is looking (typically, this happens 30 times per sec), which is also known as gaze. Gaze is captured in two forms: as saccades (quick eye movements between two fixations) and as fixations, where the focus of attention is on a certain area for at least one tenth of a second. In this experiment, the allowed dispersion was 100 screen pixels, and the duration required was at least $100 \mathrm{~ms}$.

Previously designed stimuli were utilized; these images and collages replicated the store shelves in the luxury perfume category. The order of the images on the shelf was randomized for each participant, and each participant was asked to view them freely. Since customers spend approximately $10 \mathrm{sec}$ in front of the shelf per category (Orquin and Scholderer 2011; Chandon et al. 2007) - more precisely, it ranges from 8 to $13 \mathrm{sec}$ (Hoyer 1984) - the exposure of $10 \mathrm{sec}$ per participant was considered valid. This length of time has also been utilized in similar package evaluation studies (e.g., Husić-Mehmedović et al. 2017). The stimuli consisted of three tasks and presentations: a) the silhouettes (forms) of bottles, as the perfume bottle shape is often specific and utilized for promotional purposes; b) simulation of the perfume shelf with bottles and packages, as usually perfumes are presented only in the package (not without it), and c) individual bottles with predefined areas of interest (AOIs). Products on the shelf were presented as clearly distinctive and as sufficiently large objects with an appropriate distance between them, which is an important guideline in eye-tracking research (Orquin, Ashby, and Clarke 2016).

\subsection{Survey}

The participants were instructed to complete the questionnaire before and after the eye-tracking experiment. In the questionnaire before the eye-tracking experiment, familiarity with brands and usage was assessed. The questionnaire after the eye-tracking experiment measured perception, recall, and purchase intention. Brand recall was measured utilizing the one-item scale developed by Keller (1993), while the purchase intention was measured utilizing five items from Dodds, Monroe, and Grewal (1991). Purchase intention answers were captured on a 5-point Likert scale and analyzed with descriptive statistics as well as bivariate correlations among variables in which the brand was the unit of analysis. The recall answer was captured through an open-ended question to identify the "top-of-mind" luxury perfume brand, where we defined memory probe as a cue.

\section{FINDINGS}

The present findings comprise preexperimental data, eye-tracking data, and postexperimental survey data. All data was utilized to answer previously developed research questions and to add to existing knowledge regarding the visual and behavioral patterns in luxury perfume shoppers.

\subsection{Preexperiment}

The preexperiment survey was mainly utilized to test participants' familiarity and experience with the perfume brands in general as well as the brands that were included in the research as market leaders. In the open-ended question that was asked to induce spontaneous top-of-mind perfume brands the following brands were listed on top as responses: Chanel, Dior, Armani Code, Dolce Gabbana (DG) Light Blue, and Dior Addict.

For the consumers' familiarity with the 20 previously identified brands, the following brands were mentioned by participants: DG Light Blue, YSL Opium/Black Opium, and Chanel N05. DG and Chanel appeared in both spontaneous top-of-mind and familiarity answers. Respondents were least familiar with Thiery Mugler Angel and Clinique Happy. Furthermore, the respondents had previous experience with DG Light Blue, Lancôme La Vie Est Belle, Chanel N05, Versace Bright Crystal, and YSL Opium/Black Opium perfumes. This means that respondents recently purchased one of these perfumes either for themselves or as a gift. This list aligns with the familiarity list.

In conclusion, respondents were familiar overall and had previous experience with the perfumes that were labeled as the top in the category on the market. Visual data demonstrate somewhat different results. 


\subsection{Eye Tracking Experiment}

The heatmaps illustrate that the participants' attention was not tied to the center of the shelf or the image; rather, it connected to the leading brand or a specific color and design. To assess the bottle shape effect, silhouettes of the bottles were utilized to provide ecological validity for this salience factor only (Figure 1). The specific shapes of the bottle attracted more attention on the shelf, similar to the color effect, which is presented in Figure 2, where the packages with flamboyant colors were introduced. Thus, for instance, Clinique attained the majority of the attention, even in high TFT, assuming that its orange bottle stood out in the crowd of milder colors.

Besides heatmaps, the Areas of Interest (AOIs) were assessed previously created and coded for each perfume bottle and the zone on the shelf (up-left, up-middle, up-right, down-left, down-middle, and

Figure 1. Heatmaps of the virtual shelf in silhouette

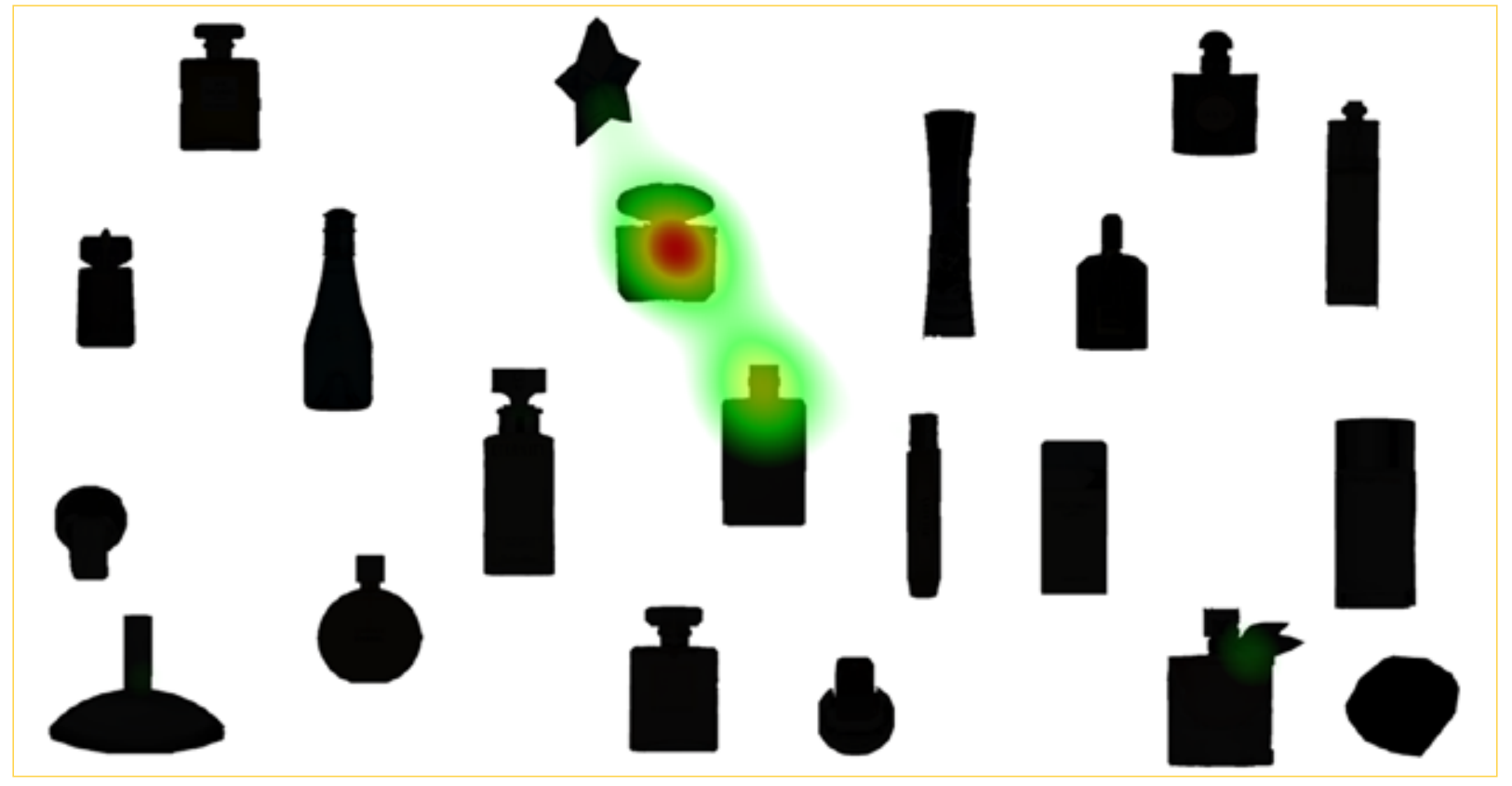

Figure 2. Heatmaps and Areas of Interest of the virtual shelf with packages

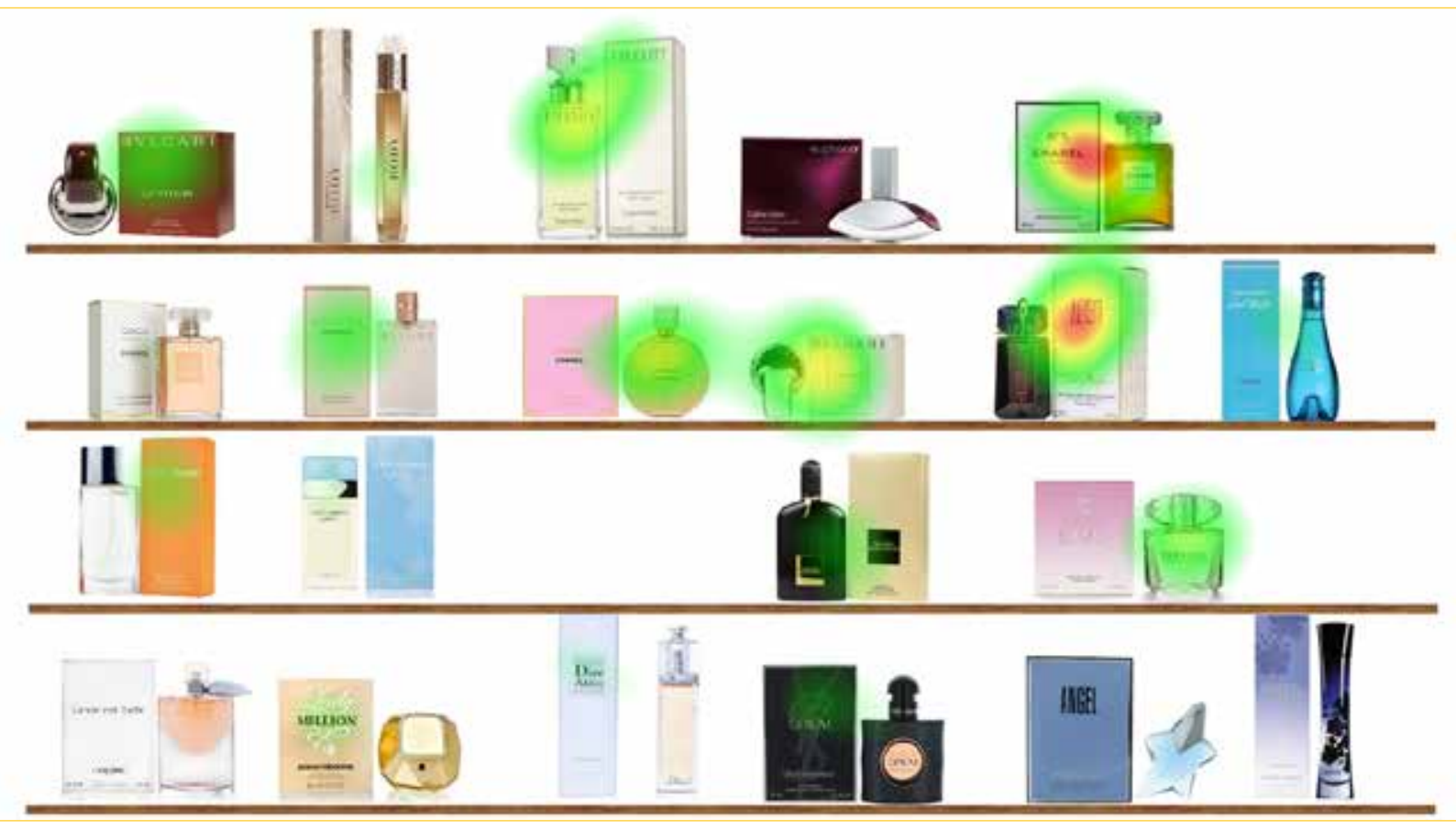


Table 1. Top three brands for different categories of eye-tracking measures

\begin{tabular}{|c|c|c|c|}
\hline \multicolumn{4}{|c|}{ Silhouettes } \\
\hline Total fixation time (s) & Fixation number & Avg. Fixation duration (s) & Saliency \\
\hline $\begin{array}{l}\text { Calvin Klein Euphoria } \\
\text { (35167) }\end{array}$ & $\begin{array}{l}\text { Calvin Klein Eurphoria } \\
\text { (119) }\end{array}$ & $\begin{array}{l}\text { Davidoff Cool Water } \\
(1097)\end{array}$ & $\begin{array}{l}\text { Burberry Body } \\
\text { (16) }\end{array}$ \\
\hline $\begin{array}{l}\text { Lancome } \\
(31436)\end{array}$ & $\begin{array}{l}\text { Lancome } \\
\text { (93) }\end{array}$ & $\begin{array}{l}\text { One Million } \\
(1069)\end{array}$ & $\begin{array}{l}\text { Channel } 5 \\
\text { (11) }\end{array}$ \\
\hline $\begin{array}{l}\text { Versace Bright Crystal } \\
\qquad(28480)\end{array}$ & $\begin{array}{l}\text { Versace Bright Crystal } \\
(82)\end{array}$ & $\begin{array}{l}\text { Channel } 5 \\
(981)\end{array}$ & $\begin{array}{c}\text { Channel Chance } \\
\text { (8) }\end{array}$ \\
\hline \multicolumn{4}{|c|}{ Shelves } \\
\hline Total fixation time & Fixation number & Avg. Fixation duration & Saliency \\
\hline $\begin{array}{l}\text { Versace Bright Crystal } \\
\text { (70279) }\end{array}$ & $\begin{array}{l}\text { Versace Bright Crystal } \\
(242)\end{array}$ & $\begin{array}{l}\text { Davidoff Cool Water } \\
\qquad(2791)\end{array}$ & $\begin{array}{l}\text { Calvin Klein Euphoria } \\
(35)\end{array}$ \\
\hline $\begin{array}{l}\text { Clinique } \\
(64748)\end{array}$ & $\begin{array}{l}\text { Lancome } \\
\qquad(215)\end{array}$ & $\begin{array}{l}\text { Paco Rabanne One Million } \\
\qquad(2694)\end{array}$ & $\begin{array}{l}\text { Bvlgari } \\
(24)\end{array}$ \\
\hline $\begin{array}{l}\text { Lancome } \\
(64102)\end{array}$ & $\begin{array}{l}\text { Calvin Klein Euphoria } \\
(212)\end{array}$ & $\begin{array}{l}\text { Angel } \\
(2611)\end{array}$ & $\begin{array}{c}\text { Channel } 5 \\
\text { (23) }\end{array}$ \\
\hline
\end{tabular}

down-right). The attentional spotlight through eyetracking measures on AOls was observed. The measurement was the median of respondents who fixated their gaze at least once inside a particular AOI. From there, the attention measures were collected for each perfume bottle individually and summarized in the final count to obtain the dominating three brands (shape or bottle design). Table 1 lists those top three brands.

TFT represents the total time gaze is focused on a particular area. It often indicates that the object received the highest amount of attention. However, this does not necessarily mean that these objects are the most desirable ones. For instance, Clinique Happy perfume is a brand that no participant mentioned in the purchase intention or the recall. It received the highest amount of attention on the shelf, though. This only applies in TFT on the shelf where the perfumes appear in color. Clinique is in the top 3 perfumes that generated the highest TFT (together with Versace and Lancome). On each stimulus, Lancome was in proximity to Clinique so presumably, the Clinique's box color attracted attention and spread it to Lancôme. Additionally, Clinique's TFT was higher than Lancôme's but lower than Versace's.

FN as a total number of unique fixations illustrated similar outcomes as TFT. Notably, the top 3 perfumes in both silhouette and shelf stimuli were the same.

The research also examined the AFD, which represents the sum of all fixation durations divided by the number of all fixations for the selected subjects on the given AOI (Voßkühler et al. 2008). On the shelves, the AFD was longer on the bottles that were essentially more interesting (Angel, One Million, and Davidoff).
For the silhouettes, top attention receivers were brands with classic packaging. This matches the recall, which could indicate that the recognizability of the brand or overall recall can influence the recognition on the shelf when the specific design features are not prominent.

\subsection{Postexperiment}

In the recall test, a correlation was found with the brand (Chanel) rather than the actual product (Chanel Mademoiselle; see Table 2). Market leader Chanel has classic, less attractive bottles. Hence, it did not attract attention in the eye-tracking experiment, but appeared at the top in recall and purchase intention. The followers (e.g., Angel and Davidoff) attracted more attention due to the peculiarities in the bottle design, shape, or color. The attention did not indicate the purchase intention in the luxury perfume category. Depending on the brand strategy or the brand lifecycle stage, the brand can choose either to attract attention and raise awareness or to rely on tradition, brand strength, and recognition (for purchase intention and recall). The followers are attempting to break the loyalty loop by reattracting attention to the bottle.

Finally, for purchase intention, consumers demonstrated significant intentions to buy the product they identified in Table 3 as the one that they were willing to try (mean of 3.7933 with a standard deviation of .67643). Trial purchase and purchase intention are somewhat correlated, and perfume trial leads to purchase of the perfume. 
Table 2. Recall test

\begin{tabular}{|l|c|}
\hline Brand name & Recall \\
\hline Coco Chanel & $\mathbf{2 6}$ \\
\hline Calvin Klein & $\mathbf{1 5}$ \\
\hline Bvlgari Omnia (series) & $\mathbf{1 5}$ \\
\hline Paco Rabanne One Million & 12 \\
\hline Dolce Gabbana Light Blue & 11 \\
\hline Versace Bright Crystal & 10 \\
\hline Lancome La Vie Est Belle & 9 \\
\hline YSL Opium / Black Opium & 9 \\
\hline Thierry Mugler Alien/ Angel & 9 \\
\hline Dior Addict & 7 \\
\hline Tom Ford Black Orchid & 6 \\
\hline Burberry Body & 5 \\
\hline Clinique Happy & 2 \\
\hline Davidoff Cool Water & 1 \\
\hline Giorgio Armani Code & 0 \\
\hline
\end{tabular}

In assessing trial and purchase intention (based on Ajzen and Fishbein 1980), the results do not follow visual data and visual attention span. The majority of the respondents would try Tom Ford (Table 3). However, they stated that they have not had the experience with it, nor have they noticed it on the shelves according to the pre-experiment and eye-tracking data.

Table 3. Willingness to try the perfume

\begin{tabular}{|l|c|}
\hline Brand & Frequency \\
\hline Tom Ford Black Orchid & $\mathbf{1 1}$ \\
\hline Dior Addict & 5 \\
\hline Chanel Coco Mademoiselle & 4 \\
\hline Chanel Chance & 4 \\
\hline YSL Opium / Black Opium & 4 \\
\hline Bvlgari Omnia (series) & 4 \\
\hline Versace Bright Crystal & 4 \\
\hline Dolce Gabbana Light Blue & 3 \\
\hline Thierry Mugler Alien & 3 \\
\hline Burberry Body & 3 \\
\hline Lancome La Vie Est Belle & 2 \\
\hline CK Euphoria & 1 \\
\hline Chanel Allure & 1 \\
\hline Davidoff Cool Water & 1 \\
\hline
\end{tabular}

\section{DISCUSSION}

\subsection{How does brand familiarity influence visual attention?}

Familiarity with the brand does not influence visual patterns. Those brands that are most familiar to shoppers and those with which they have previously had experience do not necessarily receive focused attention on shelves. Theoretically, brand familiarity and previous experience with the brand are conceptually different. Consumers can be familiar with a brand without necessarily having any brand usage experience (Simmonds et al. 2020). However, brand usage increases brand familiarity. Therefore, for the purpose of this study, these two concepts were merged into brand familiarity, which was observed in relation to other variables. According to the experiment, the attention on the shelves may be attached to those brands that consumers are the least familiar with (e.g., Clinique). The results from the preexperiment and eye tracking experiment answer RQ1: How does brand familiarity influence visual attention? Brand familiarity does not have a direct influence on visual attention on the shelf in the luxury perfumes category. This is different from existing advertising research assumptions, which argue that consumers pay attention to brands they usually buy and know (Simmonds et al. 2020). This is one of the main obstacles for brands in reaching new customers and enticing them to purchase. This research confirmed the same finding for the category leader. The visual attention on the shelf in the luxury perfumes category was driven by the leader of the category (Chanel). However, it was also discovered that attention was influenced by stand-out color and design (Clinique). It can be further argued that Chanel, as market leader, was familiar to the respondents and therefore drew their attention (according to the existing research). Additionally, other factors such as color and design had a moderating effect on attention on the perfume shelf. Previous research explains that different factors influence consumer visual attention, including contrast, color, surface size of the object, and object position (Orquin et al. 2020). This is part of saliency, which examines the relationship between the object and its surroundings.

\subsection{How do package features change common knowledge on shelf management?}

Moreover, the present eye-tracking results indicated that respondents indeed noticed the perfumes that have specific design features. Those perfume bottles are distinct, and respondents fixated on them 
because of the bright color (Clinique's box is orange), contrast, or color shading on the bottles or because of the contrast between the bottle and the box (Versace and Lancôme). The duration of the glance was the highest on bottles that had an unusual shape and design (Angel, One Million, and Davidoff). These results align with the assumption posited by Orquin and colleagues (2020) that contrast, color, or size can influence attention. Davidoff has the shape of a lighthouse in a bright blue color, One Million has a golden shape of a diamond, and Angel is in a purple, starshaped bottle. Considering the package features, RQ2 is answered: How do the package features change the common knowledge of shelf management? The brands that drew attention provoked the expectations with their unusual design. Bottom-up factors such as salience, size, and distance from the center are expected to influence consumer attention (Orquin et al. 2020). Orquin and colleagues (2020) additionally demonstrate that in addition to bottom-up factors, the brand and category can influence attention. The aforementioned perfume brands behave like attention seekers, and by design, they want to challenge the market leaders - those brands that are expected to be noticed on shelves. Moreover, the observed shift of attention from the middle of the shelf to the attention-seeking brands illustrates that the packages indeed draw attention and influence visual patterns. However, the silhouettes' absence of color and design features allowed the classic packaging of the recognizable brands to assume the lead (see Table 1). This is likely due to top-down processes, such as consumers perceiving the brand and category as important (Orquin et al. 2020) and therefore directing attention toward those objects. Concurrently, the respondents did not recall the brands with extraordinary designs, although they did recall the market leaders. In the absence of the package features, the attention seekers remained silent. However, did package features and attracted attention increase a product's purchase potential as well? This leads to the next stage of the research.

\subsection{Is the effect of attentional spotlight only subliminal, or does it transfer to consciousness and evoke purchase intention?}

According to the obtained data, the respondents stated that they would both test and purchase the perfume that did not appear in the top results of visual patterns analysis. The top 3 brands respondents chose were Tom Ford, Dior, and Chanel, indicating that the attentional spotlight and the purchase intention are variables that do not move in the same direction and are not mutually conditioned. The decision to buy perfume or other luxury products tends to be influenced by the consistency of the brand image and internal beliefs. This aligns with the theories that consumers combine and project brand's personality with and on their own personality (Park and John 2010). Bian and Forsythe (2012) indicate that social-function attitudes toward brands impact purchase intention for luxury brands both directly and indirectly. This means that luxury brand managers can adapt marketing strategies to convince consumers of the brand's upscale social image. To answer RQ3, the effect of the attentional spotlight does not evoke purchase intention. This may indicate that individuals are motivated to purchase luxury goods not because they are distinct on the shelf but for utilitarian purposes or symbolic meanings behind the brand (Aw et al. 2021).

\subsection{Is the category captain the true captain of the shelf?}

Based on the preliminary research and interviews with the market expert, Chanel was defined as the market leader in luxury perfume brands. Chanel, recognizable for its traditionally simple bottle, behaved differently in the eyes of shoppers. Examining the market leader and its behavior through eye tracking, pre- and postexperiment results contributed to answering RQ4: Is the category captain the true captain of the shelf? Approximately $8 \%$ of respondents stated that they would test Chanel perfumes ( $\mathrm{N}^{0} 5$ and Mademoiselle); in this study's total count, these perfumes appeared in 3rd and 4th positions on the purchase intent scale. The majority of respondents $(n=26)$ recalled Chanel in the brand recall scale measurement, making it the top-of-mind brand. The respondents mentioned Chanel in the questionnaire for familiarity and previous experience. The positive relationship between prior brand usage and recall might be caused by brand users paying more attention to a brand's advertising (Simmonds et al. 2020). In observing saliency, Chanel No5 appeared in the top 3 when considering both silhouettes and bottles on the shelves. In AFD, it was highly positioned as well. However, Chanel, as a brand did not appear in the top 5 list of TFT or FN, which means that it does not drive the attention on the shelf. This said, the category captain is the captain of the mind in purchasing intention and recall; however, it is not the captain of the shelf, as its simplistic bottle design does not draw attention. 


\subsection{Is shelf management irrelevant in the luxury perfume category?}

In luxury perfumes, which are sensory products, emotions are highly relevant. Moreover, brand loyalty is higher, making it more personal and less likely that consumers make frequent changes. For brands, this means that competition is fierce. Summarizing the findings from the exploratory results, this research addresses RQ5: Is shelf management irrelevant in the luxury perfume category? To answer this question, the results from eye tracking with the postexperiment questionnaires were compared. Despite brands with interesting packaging drawing attention on the shelf, luxury perfume shoppers tended to stay with either their personal choices, which aligned with previous experience, or with the fashion mainstream to belong to the group of people in trend. As support for the first case, Carey and colleagues (2016) demonstrate that $53 \%$ of respondents have no plans to change their fragrance; research suggests that loyalty is a more complex notion than other fashion or luxury products, as it intertwines deeply with areas of nostalgia, selfidentity, and brand attachment. In the case of trend following, consumers from different layers of social groups buy luxury brands to achieve a common goal: demonstrating their prestige status; luxury brands are thus associated with the antecedents of group perception - goal and concept similarity (Rashid and Chattaraman 2019) - and fulfill the desire to be trendy.

\subsection{To what extent do luxury perfumes benefit from the fashion mainstream?}

The results that illustrated the purchase intention for Tom Ford, a fragrance that did not appear in other results, may indicate several things. Tom Ford represents fashion and luxury, and the brand is known for its provocative, seductive ads. In the open-ended question regarding why they preferred purchasing this brand, respondents' answers were categorized as follows: good reviews or recommendations, interesting and intriguing bottle or design, and good marketing. Previous research has demonstrated that brand personality has a positive and significant impact on brand love, resistance to negative information, and self-disclosure; brand love has a positive and significant impact on brand loyalty, word of mouth, resistance to negative information, willingness to pay more, self-disclosure, and active engagement (Rashid and Chattaraman 2019). Tom Ford's campaigns have long been at the center of the controversy, and they consistently attract attention. Researchers have found controversy in advertising to be effective in garnering the viewer's attention or their interest (Adomaitis and Saiki 2019). In 2015, complaints against the perfume's advertisement were submitted to the British Advertising Standards Authority, which allowed Tom Ford to maintain the advertisement. Considering these points, RQ6 was evaluated: To what extent do luxury perfumes benefit from the fashion mainstream? The results indicate that luxury perfumes can benefit from the fashion mainstream in consumers' intention to test the product and to purchase it. Previous research has proven that consumers perceive themselves as having the brand's personality after they utilize the brand (Park and John 2010). Brands offer a variety of opportunities for consumers to express who they are and who they want to be. Existing research argues that one prominent usage of fashion is to develop a sense of personal identity and to develop a belief that others will notice and care about one's fashion statement (Thomson and Haytko 1997). Recent discoveries illustrate that consumers' purchase intention is not directly driven by brand prominence, but it highly depends on consumers' interpretation toward that prominence, which hinges on the personal beliefs they uphold (Aw et al. 2021).

In summary, brand familiarity has little to no influence on the attention allocated to the shelves in the luxury perfumes category. The brands that attracted attention were noticeable because of their unusual design or color, and these factors are expected to influence consumer attention. However, the allocated visual attention does not predict the purchase intention. The eye movements create an assumption about attention, but it is important to highlight the benefit of combining eye tracking with other methods for deeper understanding. The decision to buy perfume or other luxury products tends to be influenced by the consistency of the brand image and internal beliefs. Consequently, the market leader prevailed for purchasing intention and recall; however, it was not the captain of the shelf, as its simplistic bottle design did not draw attention. This leads to another conclusion. Despite brands with interesting packaging attracting attention on the shelf, luxury perfume shoppers intend to buy brands that align with previous experience or brands that are in the fashion mainstream. These results enable shelf managers and marketers to place their perfumes both on the shelf and in consumer minds. Therefore, the present research illustrates that luxury perfumes can benefit from the fashion mainstream in intention to test the product and to purchase it; furthermore, positioning in the luxury perfume market can influence the basic perception on the shelf. These insights may support the correct positioning to maintain a top-of-the-mind brand placement. 


\section{CONCLUSION}

These findings contribute to understanding of the relationship between attention and shelf management as well as with purchase intention and recall of luxury perfume brands. The study results also pose marketing implications for luxury brand marketers. Different brand's marketing communication strategies may yield results in product trials and purchases if they know their target market. Moreover, luxury perfume shoppers tend to remain loyal to their familiar brands in consumption habits, and provoking attention on the shelf with an interesting design or the color may not induce the purchase.

However, several limitations need to be considered. This research was valid in achieving the study's objectives and following the recommended sample size for eye-tracking studies; nevertheless, the size sample was small, and this influenced the statistical results. The generalizability of the results could be limited by the size. Moreover, the research model was focused on purchase intention and recall, while considering other aspects, such as likeability, price, and logo design, to be negligible or constant. Based on these limitations, some courses for future studies are suggested. First, future studies should expand the diversity and size of the sample to increase its generalizability. Additionally, it would be fruitful for future research to extend the current research model by incorporating different dimensions of self-concept for a more comprehensive understanding of brand relation and identity. Regarding the concept of the fashion statement in the luxury perfumes industry, future research should include more luxury perfume products that have strong, provocative, and extraordinary marketing to draw more general conclusions on the influence of the fashion mainstream on this category in different aspects (perception, brand image, purchase intention, post purchase behavior, and loyalty).

\section{REFERENCES}

Aaker, J. L. 1997. Dimensions of brand personality. Journal of Marketing Research 34 (3): 347- 356.

Adomaitis, A.D. and Saiki, D. 2019. Brand personality and sexuality levels of luxury advertisements. Journal of Fashion Marketing and Management 23 (4): 572-586.

Ajzen, I. and Fishbein, M. 1980. Understanding attitudes and predicting social behavior. Englewood Cliffs, NJ: Prentice-Hall.

Alba, J.W. and Hutchinson, J.W. 1987. Dimensions of consumer expertise. Journal of Consumer Research 13 (4): 411-454.
Alaoui-Ismaili, O., Vernet-Maury, E., Dittmar, A., Delhomme, G., and Chanel, J. 1997. Odor hedonics: connection with emotional response estimated by autonomic parameters. Chemical senses 22 (3): 237-248.

Aw, E.C-X., Chuah, S.H-W., Sabri, M.F., and Basha, N.K. 2021. Go loud or go home? How power distance belief influences the effect of brand prominence on luxury goods purchase intention. Journal of Retailing and Consumer Services 58 (Jan. 2021)

Aydınoğlu, N. Z., and Sayın, E. 2016. Sensory and neuromarketing: about and beyond customer sensation. In Flavor: From Food to Behaviors, Wellbeing and Health, edited by P. Etiévant, E. Guichard, C. Salles and A. Voilley, 397-408. UK: Woodhead Publishing.

Baer, T., Coppin, G., Porcherot, C., Cayeux, I., Sander, D., and Delplanque, S. 2018. Dior, J'adore: The role of contextual information of luxury on emotional responses to perfumes. Food Quality and Preference 69 (Oct): 36-43.

Belk, R. W. 1988. Possessions and the extended self. Journal of consumer research 15 (2): 139-168.

Bensafi, M., Rouby, C., Farget, V., Vigouroux, M., and Holley, A. 2002. Asymmetry of pleasant vs. unpleasant odor processing during affective judgment in humans. Neuroscience letters 328 (3): 309-313.

Berthon, P., Pitt, L., Parent, M., and Berthon, J. P. 2009. Aesthetics and ephemerality: observing and preserving the luxury brand. California management review 52 (1): 45-66.

Bialkova, S. and van Trijp, H. 2010. What determines consumer attention to nutrition labels? Food Quality and Preference 21 (n): 1042-1051.

Bialkova, S., Grunert, K.G., and van Trijp, H. 2013. Standing out in the crowd: The effect of information clutter on consumer attention for front-of-pack nutrition labels. Food Quality and Preference 41 (2013): 65-74.

Bian, Q. and Forsythe, S. 2012. Purchase intention for luxury brands: A cross cultural comparison. Journal of Business Research 65 (2012): 1443-1451.

Bigne, E., Llinares, C., and Torrecilla, C. 2016. Elapsed time onfirst buying triggers brand choices within a category: Avirtual reality-based study. Journal of Business Research 69 (2016): 1423-1427.

Bucher, H. J., and Schumacher, P. (2006). The relevance of attention for selecting news content. An eye-tracking study on attention patterns in the reception of print and online media. Communications 31 (3): 347-368.

Carey, L., Stewart, A., and Walkinshaw, S. 2016. Luxury perfume brands: Consumer Brand Relationship and the mature consumer. In Anonymous Global Fashion Conference Proceedings.

Chandon, P., Hutchinson, J. W., Bradlow, E. T., and Young, S. H. 2009. Does in-store marketing work? Effects of the number and position of shelf facings on brand attention and 
evaluation at the point of purchase. Journal of Marketing 73 (6): 1-17.

Chandon, P.J., Hutchinson, W., Bradlow, E.T., and Young, S. 2007. Measuring the Value of Point-of-Purchase Marketing with Commercial Eye-Tracking Data. In Visual Marketing: From Attention to Action, edited by M. Wedel and R. Pieters, 225- 258. New Jersey: Lawrence Erlbaum Associates.

Clement, J., Kristensen, T., and Grønhaug, K. 2013. Understanding consumers' in-store visual perception: The influence of package design features on visual attention. Journal of Retailing and Consumer Services 20 (2013): 234-239.

Cuesta, F., Paida, G., and Buele, I. 2020. Influence of Olfactory and Visual Sensory Stimuli in the Perfume-Purchase Decision. International Review of Management and Marketing 10 (1): 63-71.

Dodds, W.B., Monroe, K.B., and Grewal, D. 1991. Effects of Price, Brand, and Store Information on Buyers' Product Evaluations. Journal of Marketing Research 28 (Aug): 307-319.

Drylie-Carey, L. and Stewart, A. 2018. Mature consumers' relationship with their perfume. Revista Mediterránea de Comunicación/Mediterranean Journal of Communication 9 (1): 363-370.

Edwards, M. 2015. Fragrances of the world. 31st ed. Australia: Fragrances of the World.

Foroudi, P., Jin, Z., Gupta, S., Foroudi, M.M., and Kitchen, P.J. 2018. Perceptional components of brand equity: Configuring the Symmetrical and Asymmetrical Paths to brand loyalty and brand purchase intention. Journal of Business Research 89 (Aug): 462-474.

Gidlöf, K., Holmberg, N., and Sandberg, H. 2012. The use of eye-tracking and retrospective interviews to study teenagers' exposure to online advertising. Visual Communication 11 (3): 329-345.

Goldberg, J. H., and Kotval, X. P. 1999. Computer interface evaluation using eye movements: methods and constructs. International journal of industrial ergonomics 24 (6): 631-645.

Helle, L. 2017. Prospects and Pitfalls in Combining EyeTracking Data and Verbal Reports. Frontline Learning Research 5 (3): 81-93.

Holmqvist, K., Nystrom, M., Andersson, R., Dewhurst, R., Jarodzka, H. and De Weijer, J. 2011. Eye-Tracking: A Comprehensive Guide to Methods and Measures. UK: Oxford University Press.

Hoyer, W. D. 1984. An examination of consumer decision making for a common repeat purchase product. Journal of Consumer Research 11 (3): 822-829.

Hubner, R., Steinhauser, M., and Lehle, C. 2010. A Dual-Stage Two-Phase Model of Selective Attention. Psychological Review 117 (2010): 759-784.
Huddleston, P., Behe, B. K., Minahan, S., and Fernandez, R. T. 2015. Seeking attention: an eye tracking study of instore merchandise displays. International Journal of Retail \& Distribution Management 43 (6): 561-574.

Husić, M., and Čičić, M. 2009. Luxury consumption factors. Journal of Fashion Marketing and Management 13 (2): 231-245.

Husić-Mehmedović, M., Omeragić, I., Batagelj, Z., and Kolar, T. 2017. Seeing is not necessarily liking: Advancing research on package design with eye-tracking. Journal of Business Research 80 (n): 145-154.

Karmarkar, U. R., and Plassmann, H. 2019. Consumer Neuroscience : Past, Present, and Future. Organizational Research Methods 22 (1): 174-195.

Keller, K.L. 1993. Conceptualizing, Measuring, and Managing Customer-Based Brand Equity. Journal of Marketing 57 (Jan): 1-22.

Kim, J.-E., Lloyd, S., Adebeshin, K., and M. Kang, J.-Y. 2019. Decoding fashion advertising symbolism in masstige and luxury brands. Journal of Fashion Marketing and Management 23 (2): 277-295.

Krajina, A. 2019. Interpretation of Online Consumer Behavior from Consumer Neuroscience Perspective- Cross Generational Study. Brno, CZ: Masaryk University Press.

Lambert-Pandraud, R., and Laurent, G. 2010. Why do older consumers buy older brands? The role of attachment and declining innovativeness. Journal of Marketing 74 (5): 104-121.

Leckner, S. 2012. Presentation factors affecting reading behaviour in readers of newspaper media: an eye-tracking perspective. Visual Communication 11 (2): 163-184.

Leppänen, J. M., and Hietanen, J. K. 2003. Affect and face perception: odors modulate the recognition advantage of happy faces. Emotion 3 (4): 315-315.

Le Guérer, A. 2002. Olfaction and cognition: A philosophical and psychoanalytic view. In Olfaction, taste, and cognition, edited by C. Rouby, B. Schaal, D. Dubois, R. Gervais, and A. Holley, 3-15. UK: Cambridge University Press.

Megehee, C. M., and Spake, D. F. 2012. Consumer enactments of archetypes using luxury brands. Journal of business research 65 (10): 1434-1442.

McClure, C. and Seock, Y.-K. 2020. The role of involvement: Investigating the effect of brand's social media pages on consumer purchase intention. Journal of Retailing and Consumer Services 53 (Mar)

Moore, R.S., Stammerjohan, C.A., and Coulter, R.A. 2013. Banner Advertiser- Web Site Context Congruity and Color Effects on Attention and Attitudes. Journal of Advertising 34 (2): 71-84.

Orquin, J., and Scholderer, J. 2011. Attention to health cues on product packages. Journal of Eyetracking, Visual Cognition and Emotion 1 (1): 59-63. 
Orquin, J. L., and Loose, S. M. 2013. Attention and choice: A review on eye movements in decision making. Acta psychologica 144 (1): 190-206.

Orquin, J. L., Ashby, N. J., and Clarke, A. D. 2016. Areas of interest as a signal detection problem in behavioral eyetracking research. Journal of Behavioral Decision Making 29 (2-3): 103-115.

Orquin, J.L., Bagger, M.P., Lahm, E.S., Grunert, K.G. and Scholderer, J. 2020. The visual ecology of product packaging and its effects on consumer attention. Journal of Business Research 111 (2020): 187-195.

Park, J.K. and John, D.R. 2010. Got to Get You into My Life: Do Brand Personalities Rub Off on Consumers? Journal of Consumer Research 37 (4): 655-669.

Petersson McIntyre, M. 2013. Perfume packaging, seduction and gender. Culture unbound: Journal of current cultural research 5 (2): 291-311.

Pieters, R. and Warlop, L. 1999. Visual attention during brand choice: The impact of time pressure and task motivation. International Journal of Research in Marketing 16 (1999): 1-16.

Pieters, R., Warlop, L., and Wedel, M. 2002. Breaking through the clutter: Benefits of advertisement originality and familiarity for brand attention and memory. Management Science 48 (6): 765-781.

Rambourg, E. 2014. The bling dynasty: Why the reign of Chinese luxury shoppers has only just begun. UK: Wiley.

Rashid, M. and Chattaraman, V. 2019. Do consumers react differently to sweatshop allegations on luxury and non-luxury brands? A brand entitativity-based account. Journal of Fashion Marketing and Management 23 (1): 138-155.

Rétiveau, A. N., Iv, E. C., and Milliken, G. A. 2004. Common and specific effects of fine fragrances on the mood of women. Journal of sensory studies 19 (5): 373-394.

Richmond, A. 2012. Men's and women's fragrances - UKSept. 2012. UK: Mintel Group Ltd.
Simmonds, L., Bellman, S., Kennedy, R., Nenycz-Thiel, M. and Bogomolova, S. 2020. Moderating effects of prior brand usage on visual attention to video advertising and recall: An eye-tracking investigation. Journal of Business Research 111 (n): 241-248.

Tonkin, C., Ouzts, A.D., and Duchowski, A.T. 2011. Eye Tracking Within the Packaging Design Workflow: Interaction with Physical and Virtual Shelves. Paper presented at First Conference on Novel Gaze-Controlled Applications of 2011, Karlskrona, Sweden, May.

Thomson, C.J. and Haytko, D.L. 1997. Speaking of Fashion: Consumers' Uses of Fashion Discourses and the Appropriation of Countervailing Cultural Meanings. Journal of Consumer Research 24 (Jun): 15-42.

Underwood, R.L., Klein, N. M. and Burke, R. R. 2001. Packaging communication: attentional effects of product imagery. Journal of Product \& Brand Management, 10 (7): 403-422.

Vigneron, F., and Johnson, L. W. 1999. A review and a conceptual framework of prestige-seeking consumer behavior. Academy of marketing science review 1 (1): 1-15.

Vigneron, F., and Johnson, L. W. 2004. Measuring perceptions of brand luxury. Journal of brand management 11 (6): 484-506.

Voßkühler, A., Nordmeier, V., Kuchinke, L., and Jacobs, A.M. 2008. OGAMA - OpenGazeAndMouseAnalyzer: Open source software designed to analyze eye and mouse movements in slideshow study designs. Behavior Research Methods 40 (4): 1150-1162.

Warrenburg, S. 2005. Effects of fragrance on emotions: moods and physiology. Chemical Senses 30 (1): i248-i249. 